\title{
Dos cartas inéditas de la correspondencia de Jovellanos en el archivo de Aureliano Fernández-Guerra y Orbe
}

\author{
Javier Miranda ValdéS
}

Instituto Feijoo de Estudios del Siglo XVIII

CES.XVIII, núm. 22 (2012), págs. 23-37. 
RESUMEN

Se editan dos cartas inéditas de Jovellanos a Juan Nepomuceno Cónsul y de José de Espinosa Tello a Jovellanos, depositadas en el archivo de Aureliano Fernández-Guerra y Orbe.

Palabras clave

Correspondencia, Jovellanos, Juan Nepomuceno Cónsul, José de Espinosa Tello, Aureliano Fernández-Guerra y Orbe.

\section{AbSTRACT}

Two unreleased letters, from Jovellanos to Juan Nepomuceno Cónsul and from Espinosa Tello to Jovellanos, both deposited on the archive of Aureliano Fernández-Guerra y Orbe, are published.

KEY WORDS

Correspondence Jovellanos, Juan Nepomuceno Cónsul, José Espinosa Tello, Aureliano Fernández-Guerra y Orbe.

Recibido: 09-12-2011. Aceptado: 02-03-2012. 
Con ocasión de una visita al archivo de Aureliano Fernández-Guerra, don Pedro Álvarez de Miranda tuvo oportunidad de ver entre los papeles de don Aureliano dos cartas, una de Jovellanos dirigida a Juan Nepomuceno Cónsul de fecha 30 de octubre de 1782 y otra de José de Espinosa Tello dirigida a Jovellanos de fecha 21 de enero de 1795. En las cartas, que llevaban durmiendo en su legajo más de 150 años, consta que se las había dado a Fernández-Guerra don Fermín Canella Secades. Pedro Álvarez de Miranda nos hizo ver el interés que tendría su publicación, y como persona entendida en el xvIII, pudo comprobar la primicia que suponía ponerlas en conocimiento de los estudiosos de Jovellanos.

Consultó la magna edición de José Miguel Caso González de la correspondencia de Jovellanos ${ }^{1}$. En dicha recopilación aparecen los personajes de Cónsul y de Espinosa, y al estar las cartas ordenadas cronológicamente, se comprueban los huecos que corresponderían a estas dos, desconocidas hasta ahora. Comentar el contenido de las nuevas cartas no es el objeto de esta presentación. Otros más preparados harán el análisis y las situarán en su momento histórico, enriqueciendo la biografía de Jovellanos, si no con nuevos datos, sí con comprobaciones y cotejos.

Para integrar estas dos nuevas cartas en el conjunto de la Correspondencia de Jovellanos les asignamos los números 131 bis y 689 bis, que por su fecha les corresponderían dentro de aquél.

Fernández-Guerra era Académico Bibliotecario de la Real Academia Española y Académico Anticuario de la Real Academia de la Historia. Destacó por sus estudios sobre Quevedo y su erudición sobre el Siglo de Oro en la primera, y por sus estudios geográfico-epigráficos, su colaboración con el Corpus y en los intrincados límites romanos-visigóticos, con las sucesivas limitaciones de los obispados y en su continuo trabajo sobre la interpretación de la Hitación de Wamba, en la segunda.

Fueron amigos suyos Cándido Nocedal y Fermín Canella Secades. Con el primero le unía una temprana amistad, que fue aumentando por el común interés en la erudición literaria, y en la creación y apoyo al neocatolicismo que fue creciendo para hacer frente al krausismo. Con el segundo su relación fue más

1 Gaspar Melchor de Jovellanos, Obras Completas, tomos II y III, Correspondencia. Edición crítica, introducción y notas de José Miguel Caso González. Oviedo, Centro de Estudios del Siglo XVIII - Ilustre Ayuntamiento de Gijón, 1985-1986. 
profesional que de amistad, ya que Canella era inspector de monumentos de Oviedo, puesto dependiente del Académico Anticuario. Los trabajos de Canella sobre Asturias eran seguidos por Aureliano y por él estaba informado de los trabajos epigráficos de la provincia. Cándido Nocedal fue un estudioso de Jovellanos, publicó dos tomos en la colección de Rivadeneyra, la Biblioteca de Autores Españoles (XLVI y L). Fermín Canella Secades, como buen asturiano, se interesaba por Jovellanos, adquiriendo documentos y noticias sobre él. Con lo cual ya tenemos la posible explicación de cómo llegaron a las manos de Aureliano estas dos cartas. Por un lado era sabedor de la necesidad de Nocedal de documentarse y por otro sabedor de la posibilidad de que Canella estuviera en posesión de información y datos, de lo que puede deducirse que éste le mandase a Aureliano las cartas, para que se las facilitase a Nocedal.

\section{1 bis. De Gaspar Melchor de Jovellanos a Juan Nepomuceno Cónsul}

Madrid, 30 de octubre de 1782.

Reservada

Mi mui estimado amigo:

Aunque a mi arribo hallé en mi casa una carta de vm., me proponía no contestar a ella hasta que pudiese decirle algo sobre nuestro asunto pendiente; pero habiendo recibido otra ahier, no puedo contener los estímulos de mi afecto, que me obligan a decirle que después de un rodeo, en el qual vi lo mejor de Galicia, porque corrí hasta Santiago, de allí a Vigo y volviendo a Santiago atravesé la Galicia hasta el Vierzo, llegué por fin a mi casa bueno, y según dicen todos gordo, bien que más negro que un gitano. Lo que me había detenido en otras partes me quitó de detenerme en el Sitio, donde solo estuve una noche, solo vi a mis parientes y a dos ministros. No pude por consecuencia ver todavía a nuestro caballero, que con la vuelta de estos Príncipes anda alvorotado. Ahier llegó el conde d'Artois ${ }^{2}$ y esta tarde el duque de Borbón ${ }^{3}$, que se van de carrera al Sitio ${ }^{4}$,

2 El conde d' Artois (1757-1836) sería más tarde Carlos X de Francia (1824-1830).

3 Aquí Jovellanos se refiere al duque de Borbón con su auténtico título, pero en estos momentos aparecía en España con el seudónimo de conde de Dammartin, ya que no quería hacerse notar con su presencia en el apoyo a España ante el último asedio a Gibraltar. Del Mercurio histórico y político, julio de 1782, pág. 244, copiamos: «El Señor Duque de Borbón, hijo primogénito del Príncipe de Condé, salió el 18 del corriente para Madrid, desde donde pasará a Gibraltar. Este Señor se mantendrá siempre incógnito durante su viage de España, y servirá de Voluntario en la expedición de Gibraltar baxo el título de Conde de Dammartin».

${ }^{4}$ Con «el Sitio» se refiere al Real Sitio de San Lorenzo de El Escorial, donde en esos momentos se encontraba la Corte. De la Gaceta de Madrid», $1^{\circ}$ de noviembre de 1782, copiamos: «El Sr. Conde de Artois 
para volver quanto antes a Francia. No está lejos la vuelta de la Corte a Madrid, que será a últimos del que entra; si antes no le viese, puede ser que le escriba. Le avisaré de las resultas. Entretanto celebro que vm. esté ya de acuerdo con Dóriga. La buena fee con que vm. andubo al principio formando una compañía sin fijar sus condiciones hubiera dañado mucho, para qualquiera pretensión que vm. quisiese formar. Lo mejor es ir de acuerdo en una y otra empresa, y a esto deben ayudar los amigos de entrambos. No dege vm. de decirme alguna vez los progresos de ambas fábricas porque me interesan de veras. Esa viuda dice en buenos términos que yo se lo pedí, y no lo estraño tanto por la mentira como por que haga gala de ella. A ser cierto no tendría dificultad en confesarlo, porque, como dijo Terencio, homo sum, humani nihil a me alienum puto. Pero crea vm. que quando hubiera llegado ese caso, no sólo estaría vencida la trinchera de la virtud, sino otras en que suele abrigarse y defenderse más tiempo el sexo débil. El capítulo de la Gaceta no merecía a la verdad ser objeto de murmuración, pero donde hai viudas que para pagar por algo fingen que se lo piden, ¿̨por qué no podrá haber idiotas que murmuren de lo bueno solo porque no está a la puerta de su casa? A la esposa y al hermoso niño hago mil finas expresiones y quedo de vm. con la maior ternura, fino y fiel amigo,

Jovellanos

\section{P. D.}

Procuraré buscar el marfil y enviarlo a vm. con las obras de Mengs para que vea si puede hacer algo según sus principios. ¿Pero no sería mejor que retratase vm. una viuda melindrosa, abrazando con una mano a la mentira y azotando con otra a la virtud?

Sr. Cónsul ${ }^{5}$.

entró en esta Capital el Martes después de mediodía y fue a apearse en casa del Sr. Embaxador de Francia, en donde comió, pasó la noche y comió también al día siguiente, habiendo llegado a la sazón el Sr. Conde de Dammartin. Consiguientemente partieron juntos por la tarde para el Real Sitio de S. Lorenzo y fueron recibidos por S. M. y toda la Real Familia con las mayores demostraciones de aprecio y cariño.»

${ }^{5}$ Juan Nepomuceno Cónsul fue promotor y director vitalicio de la Escuela de Dibujo de Oviedo, fundada en 1785 bajo los auspicios de la Sociedad Económica de Asturias (Fermín Canellas Secades, Noticias biográficas de Don Juan Nepomuceno Cónsul y Requejo, Oviedo, 1886). Cónsul colaboró con Jovellanos en el verano de 1782 en los decorados de las representaciones en Gijón de El delincuente honrado y El Pelayo (OC, tomo II, carta 120). Como agradecimiento por las gestiones que Jovellanos hizo para que se designara a Cónsul vicecónsul de Francia en Asturias (carta 119), Cónsul quería obsequiarle con dos miniaturas en marfil: una representa el Cupido de la casa de Valdés; la otra, una versión del primer retrato de Jovellanos por Goya, con el arenal de San Lorenzo al fondo. Según Somoza, la segunda fue heredada por Manuela Blanco Inguanzo, y de ella tenía una copia Dorotea Armiño, que era propiedad, precisamente, de Fermín Canella. Javier GonZÁLEZ SAnTos, Jovellanos, aficionado y coleccionista, Gijón, Ayuntamiento de Gijón, 1994, pág. 80. 
Sevilla, 21 de enero de $95^{6}$.

Mi amado y dulce Amigo: embuelto desde que llegué en Logaritmos, en Planos, Derroteros y Cartas Náuticas, no he podido cumplir mi palabra de escribir a vm. una larga Carta imponiéndole en nuestro viage por mayor; y con la esperanza de poder hacerlo he ido retardando de día en día esta prueva de mi memoria y de mi amor a una persona que, en medio del desagrado que causa el tiempo presente a todo hombre que piensa, me obliga a dar alguna importancia al vivir. Satisfágase pues entre tanto mi afecto y más adelante haremos por servir a la curiosidad bien puesta que debe vm. tener sobre nuestros pasos. Ya habló de ellos la Gaceta, pero con un desorden y confución, y con anuncios y promesas tales, que se habrán hecho increíbles a las personas sensatas. Aunque el tiempo presente no es apropósito para trabajar sobre estos particulares se ha dado principio de Madrid a la tarea, y de nada menos tratan que de fraguar siete tomos en quarto, con setenta u ochenta Cartas en Atlas ceparado, amén de un diluvio de dibujos, de trajes, de estampas de animales y de otros objetos de historia natural, que sobre mui costosa harán insoportable la Obra para el mayor número de lectores. Mal[aspina] está encargado de escribirla y tiene a sus órdenes los sujetos que ha elegido para que le ayuden en tan ardua empresa. Al principio creíamos haría Var[gas Ponce?] la redacción, pero se ha desvanecido esta esperanza y en lugar de ir a la Corte se pasea por Sevilla aprovechando útilmente su licencia. Yo la tengo sin haberla solicitado del mismo modo que otros de mis Compañeros que padecimos mucho en la última navegación; y a la verdad que de milagro ha escapado su Amigo de vm. y tal vez le conserva la Providencia para premiarle, con el gozo de abrazar a vm. algún día, sus males y trabajos de muchos años. En la travesía de China al Pacífico, la Nueva Olanda, Nueva Zelanda, Yslas de las Americas y Lima que nos costó 9 meses de mar, contraje un escorbuto tan arraigado que llegué a Lima en la última extremidad. No pude seguir en las Corbetas por el Cabo de Hornos y pasé a Valparaíso, y por la famosa cordillera de los Andes y las dilatadas llanuras de las Pampas atravesé toda la América Meridional y vine a reunirme con los míos en Buenos Aires y Montevideo. No me ha pesado ver esta porción la más hermosa de la tierra, y sólo me duele la precipitación con que he pasado por unos Países dignos de toda la atención de un viagero filósofo. Sobre todo el Reyno de Chile es un verdadero Paraíso, y quien pudiese reunir bajo aquel cielo los objetos de su cariño, gozaría de la mayor felicidad que puede alcanzarse acá abajo.

\footnotetext{
${ }^{6}$ En esta carta figuran las siguientes anotaciones, de letra de Fermín Canella Secades: «Fermín Canella Secades, Oviedo 1868». «Esta carta la hallé en un libro que compré, perteneciente al Sr. Colosia de Avilés, sujeto de mérito.»
} 
Mucho deseo tengo de ver el impreso que vm. me anuncia sobre el Ynstituto Asturiano, y me cabe mucha parte en el consuelo interior que dará a vm. el ser Promotor de tan útil establecimiento. Ygnoro hasta qué punto se extienda en él la instrucción y estudio del Pilotage, de esta ciencia divina que por los grandes pasos que ha hecho en estos últimos treinta años parece rayar ya con su perfección. Acavamos de perder en uno de estos días a uno de los más distinguidos Profesores, Don Vicente Tofiño ${ }^{7}$, cuya memoria durará mientras se dé algún valor al verdadero mérito, y mientras deban su seguridad nuestros $\mathrm{Bu}$ ques al excelente Atlas Marítimo que trabajó. En dicho General ${ }^{8}$ he perdido un Maestro ilustrado y un amigo el más fino. Lo era de vm. mui de corazón aunque su temple de espíritu y su filosofía estorvaban la manifestación libre de estos sentimientos, mientras la frequencia del trato no daba lugar a la intimidad. En otra nación se apresurarían mil plumas a elogiarle y proponerle como un modelo de verdadera ciencia y patriotismo; pero en la nuestra que, muerto a los 63 años de edad, hace sólo 5 que sacamos de su instrucción algún partido, y todos los demás le dejamos vivir en el abatimiento y la oscuridad, no hai esperanza de que se le haga este honor y esta justicia. Siempre tendré presentes sus últimas palabras quando me despidió para esta Ciudad, anunciándome ya la cercanía a que concideraba su fin, y que cierto por propia experiencia de la injusticia de los hombres, dejaba la vida sin pesar, así como su proceder en ella respecto a otro estado de existencia no le causaba luto.

Hablemos de cosas menos tristes. Hace pocos días que con otros Amigos comí con el Señor Bruna9. Allí tuve el gusto de conocer al Señor Altamirano, y recordamos la dulce memoria de vm. brindando a la salud y prosperidad del Patriota de Gijón, a quien yo miro como dechado de todo lo bueno y como el objeto de la más tierna amistad que profesa a vm.

Mis finas memorias al Señor Don Francisco.

Espinosa $^{10}$

Sor. Dn. Gazpar de Jovellanos.

7 D. Vicente Tofiño de San Miguel, autor del Atlas marítimo de España. Esta cartografía fue levantada por Tofiño entre 1783 y 1789.

${ }^{8}$ Se refiere a Tofiño; en aquella época la graduación de general también era aplicada a la Marina.

9 Francisco Bruna, amigo de Jovellanos y de Espinosa. Era director de la Escuela de Pintura de Sevilla y jurisconsulto. Parece que trató de buscar pintores para que acompañasen a Malaspina en su viaje. Véase Carmen Sotos Serrano, Los pintores de la expedición de Alejandro Malaspina, Madrid, RAH, 1982, pág. 68.

10 José Espinosa Tello (Sevilla, 1763-Madrid, 1815), superintendente de la Real Fábrica de Tabacos. Marino y geógrafo español. Colaboró con Vicente Tofiño en trabajos sobre la costa cantábrica. Viajó a México (1790-1794), determinando la situación de diversos escollos del Pacífico, Veracruz, México y también de los Andes. Autor de cartas marinas de la región centroamericana. Hermano de Miguel de Espinosa y Tello de Guzmán, segundo conde del Águila. 
Fermin canclla, secades. wi. $3 \%$ d 8 . dely8z.
Credo 1868

Regervata

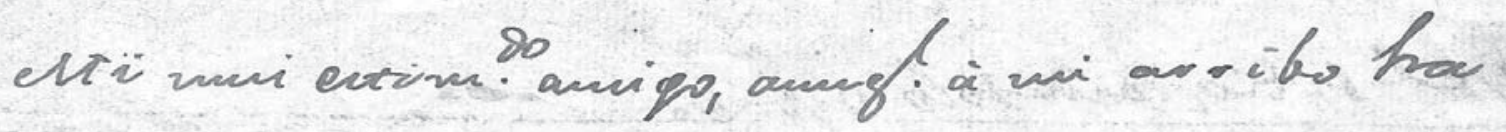

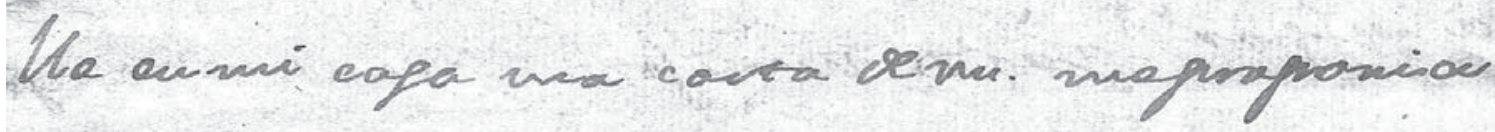
mo entestar a elle hafora 8. Juedioge decirle

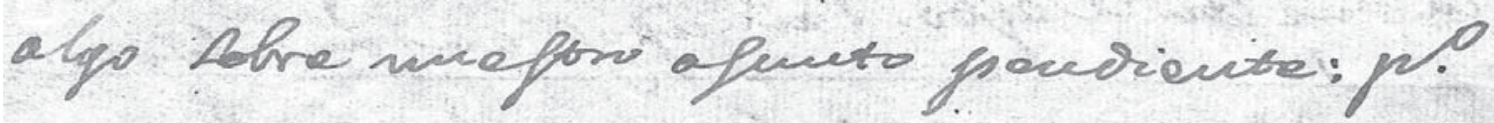
habien or necibids obra ahies no juedo cas

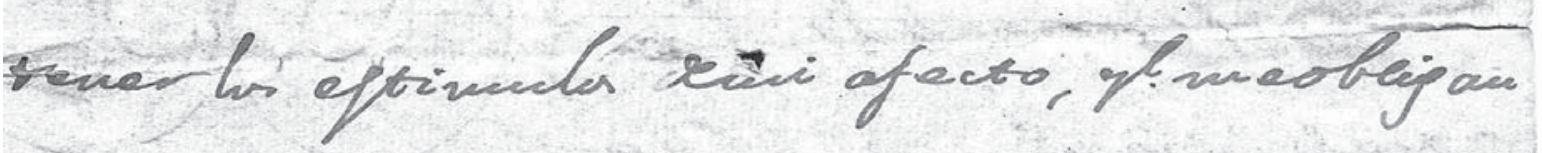
a'decille: gl. Deypuep de in rodeo, enelgpal vi: Tomejor de Salicia, plavi hapta dactiajp,

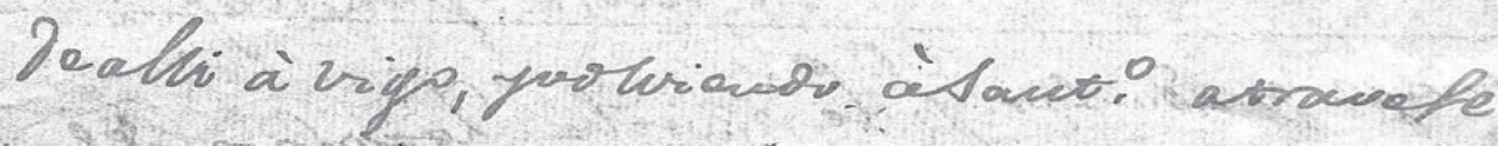

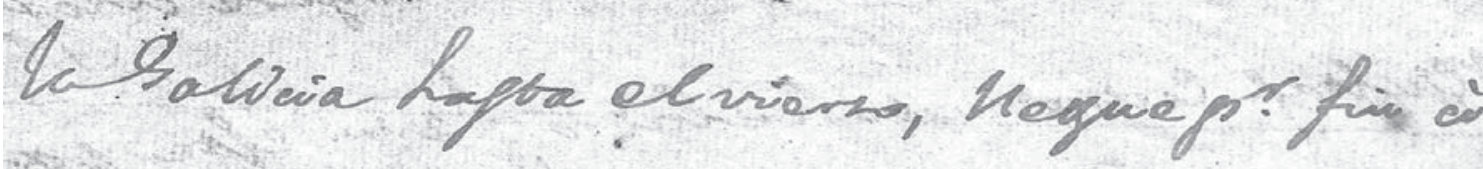
micapa buen, ytap. dicen toos gard, bieng!

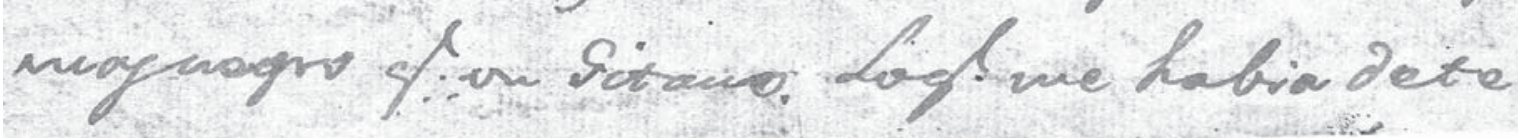

30

CES.XVIII, núm. 22 (2012), págs. 23-37 


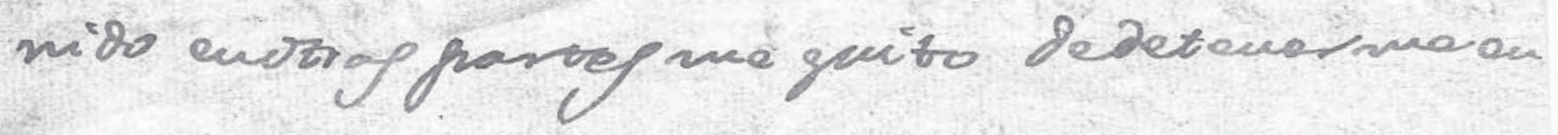

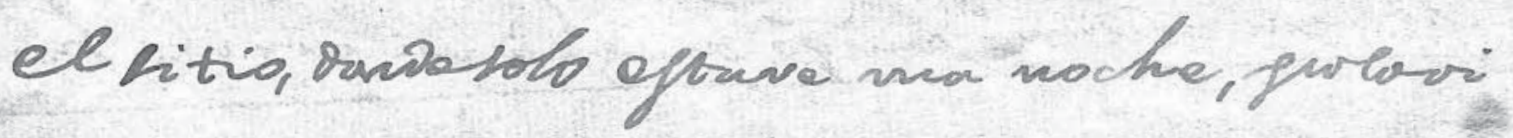

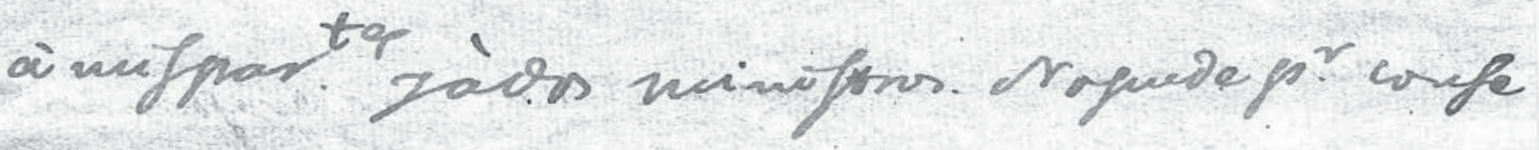

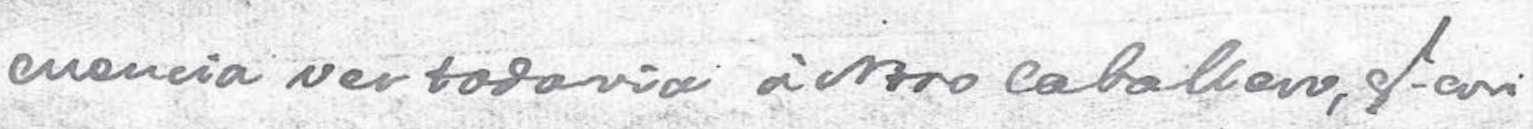

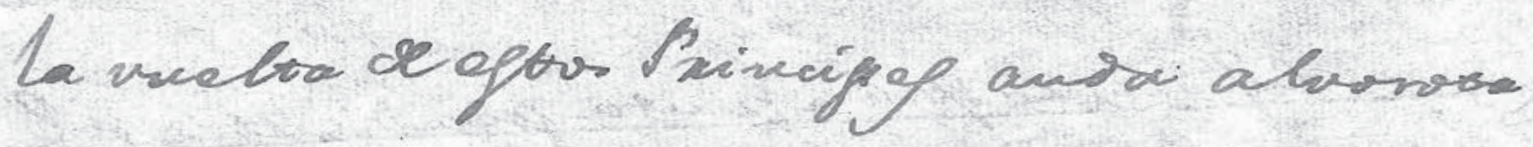

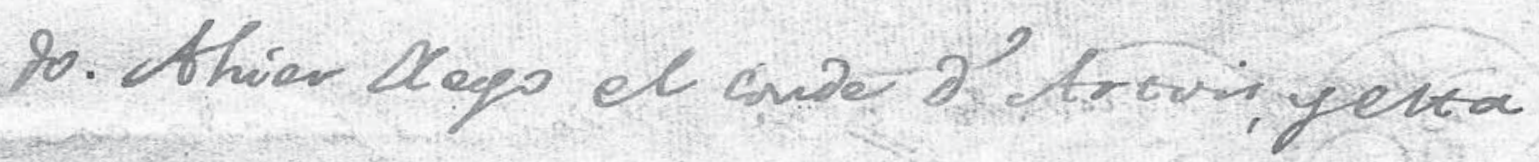

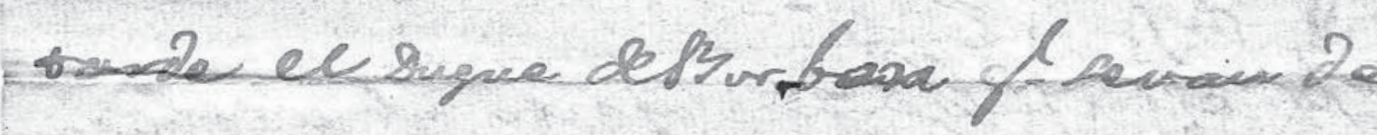

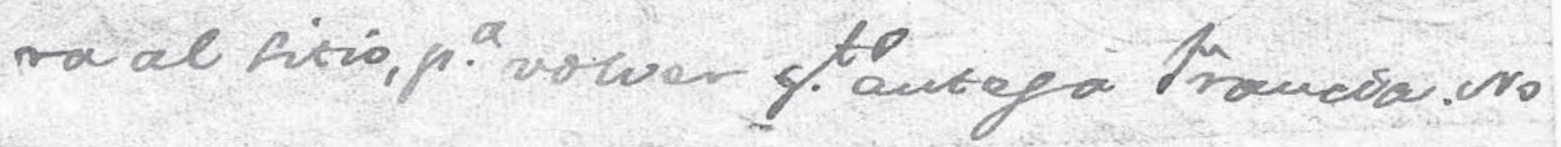
eftaleper la vareloa dela Eserer à uradxip

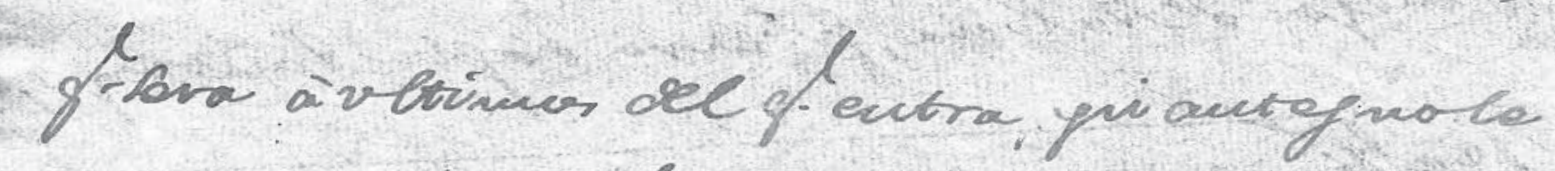

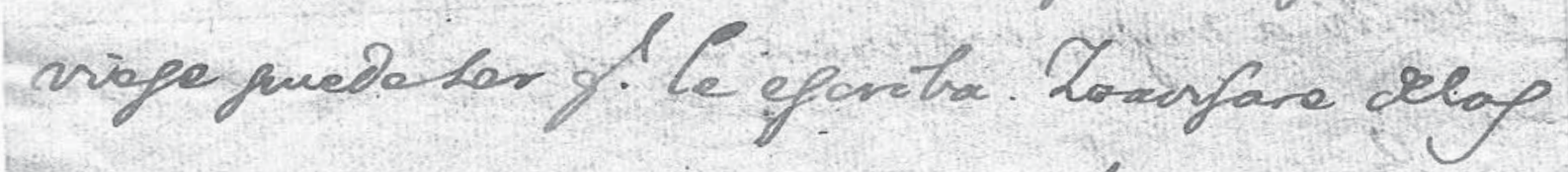

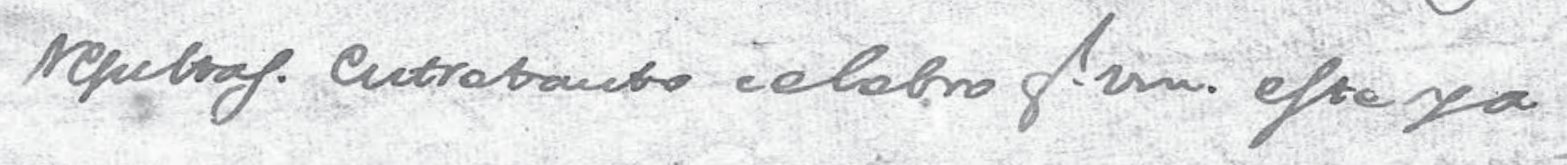
De acuense con Dorija: La hwara feé cong-un.

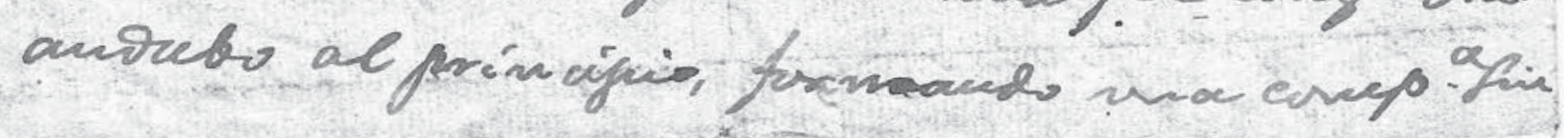

CES.XVIII, núm. 22 (2012), págs. 23-37

31 
fipar by condicionef habiora daiads nuche,

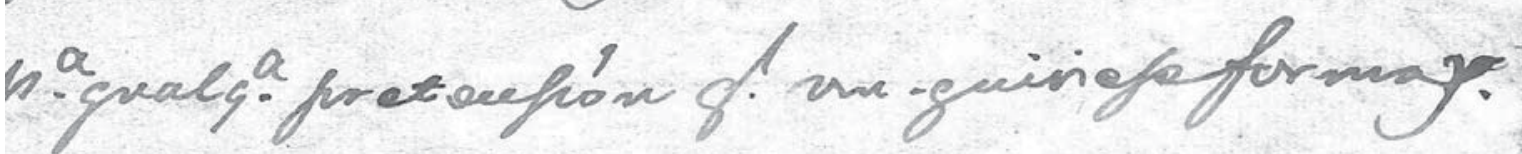

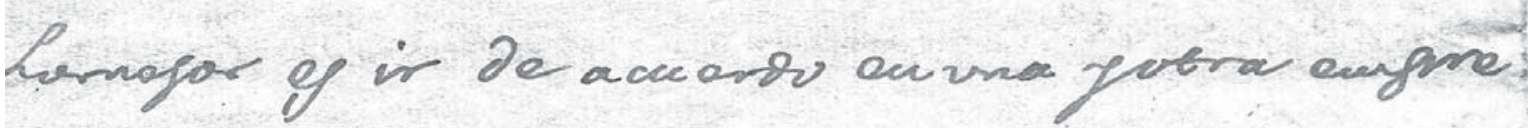
ba, pai epto debew ayperor Lor aceriges de ecr

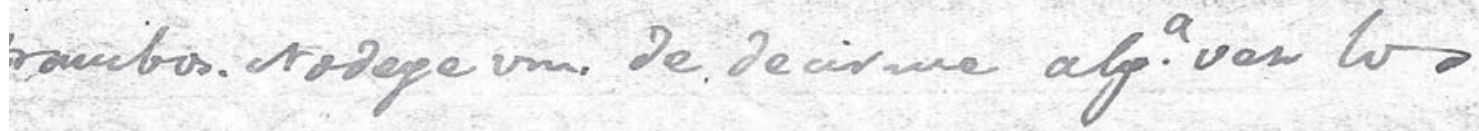

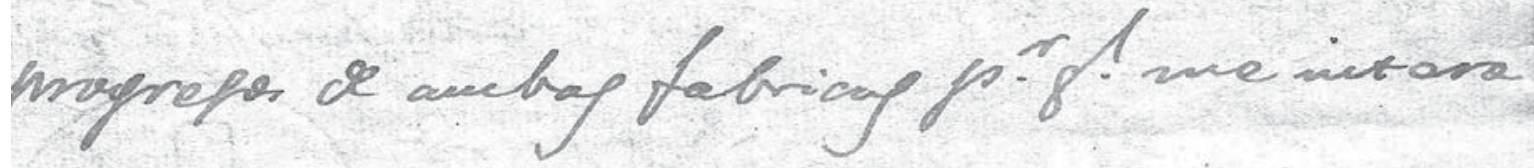

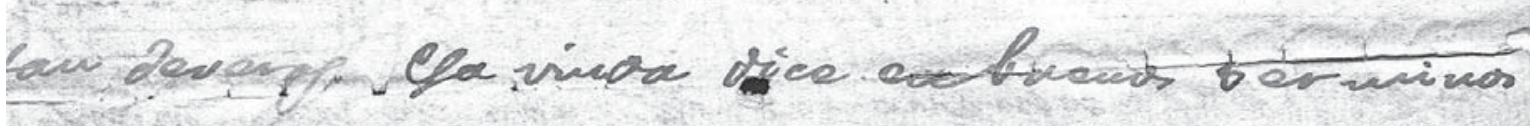

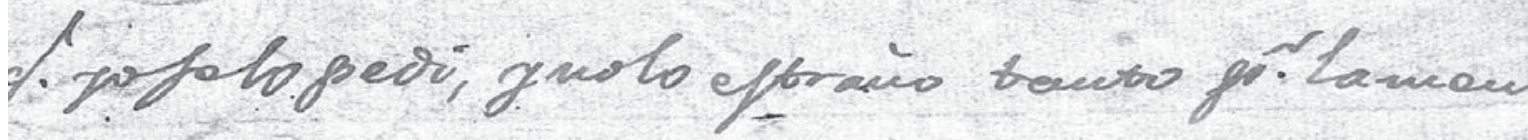
wra, eared yis. hagagela de ella. Alevcionto

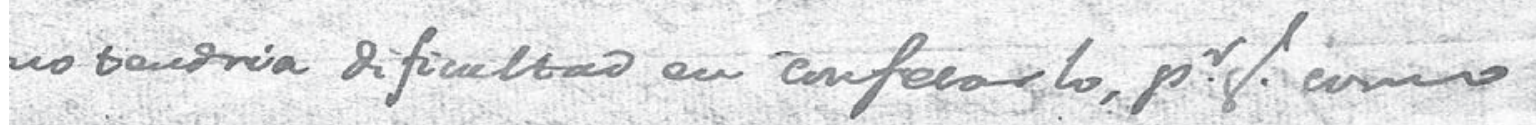

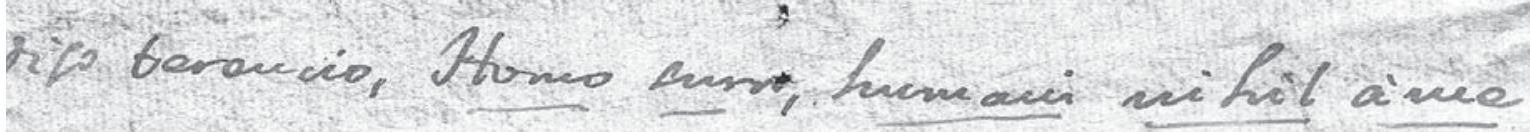

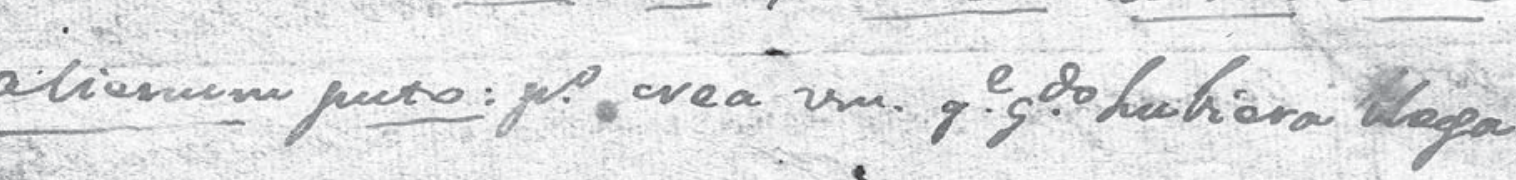
ro efe cape, nofita oforaria veucuda la trive thora dela vidtred, nino obng eugl. niolle 


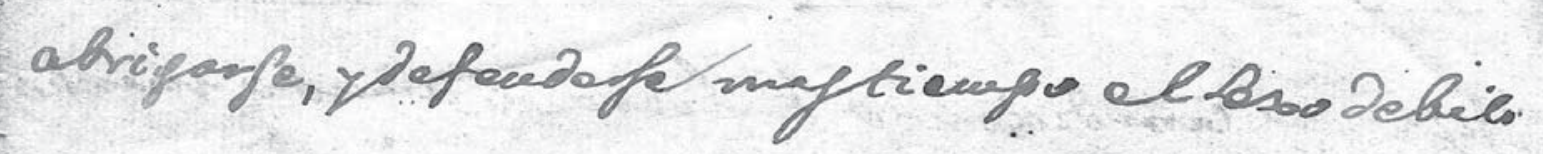

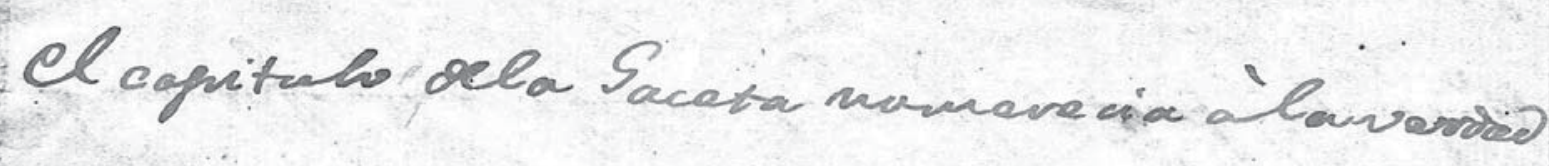
levobgets de munuviacion, po drnde haivin

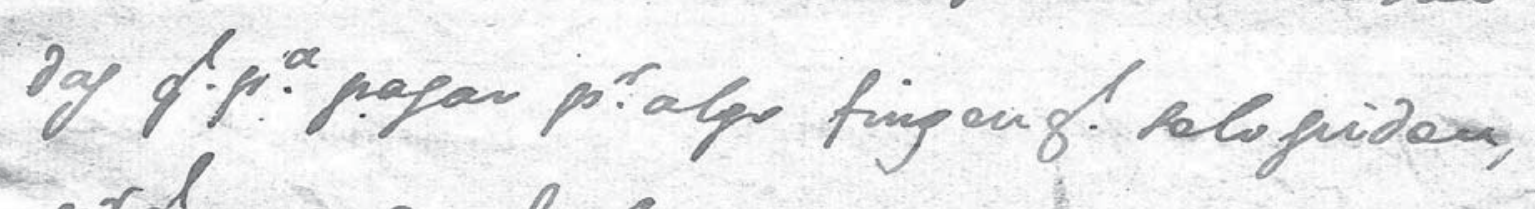

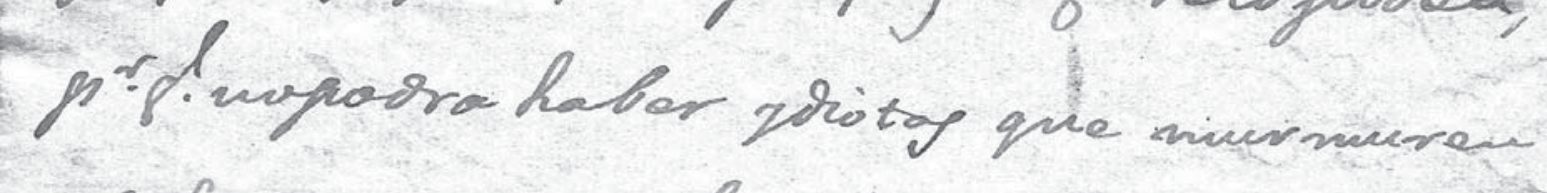
delobuano rolu gís no epíá àla puevta de hicafa? Hla eyrofaj à haveroso vinis hage

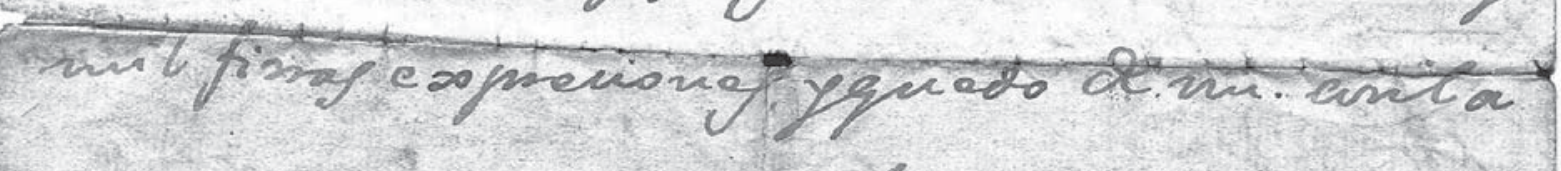
maior terwura, fino fy ficl acuigs.

I.D.

Cavederog

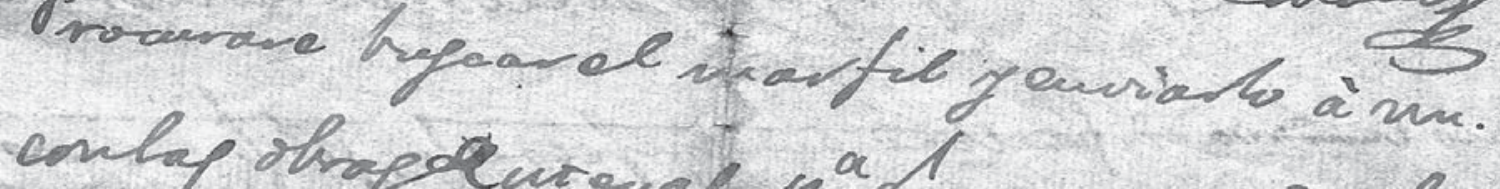

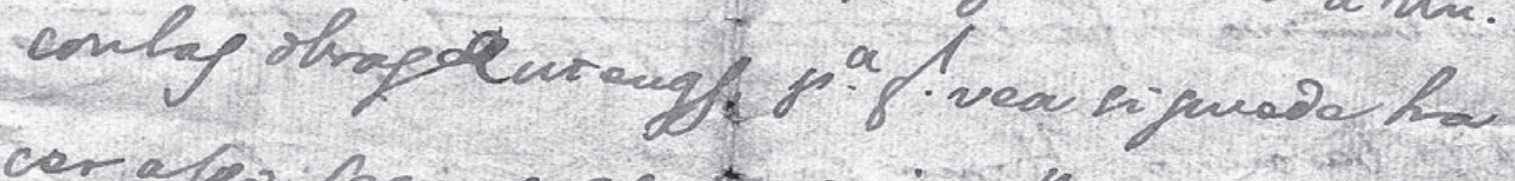

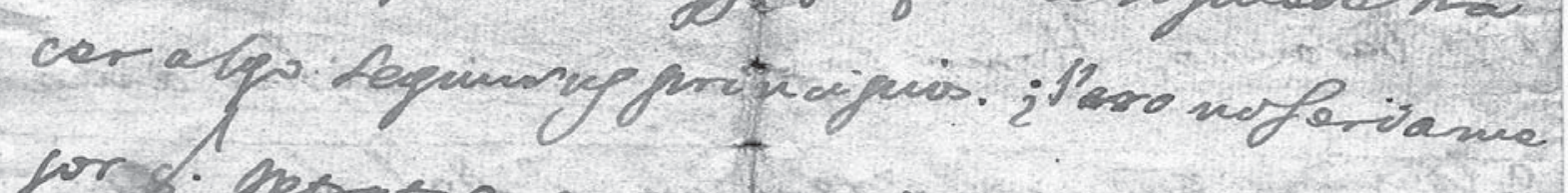

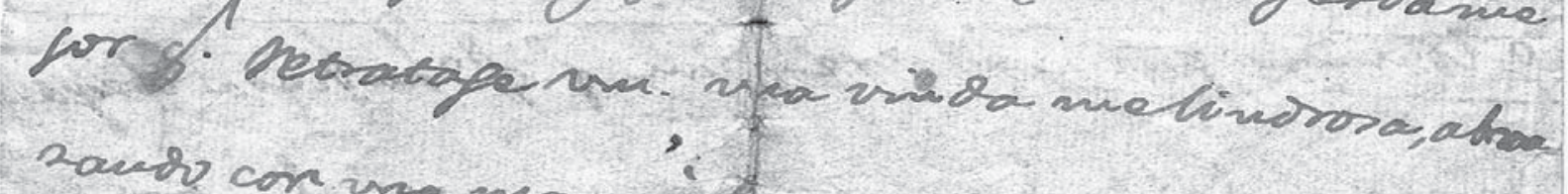

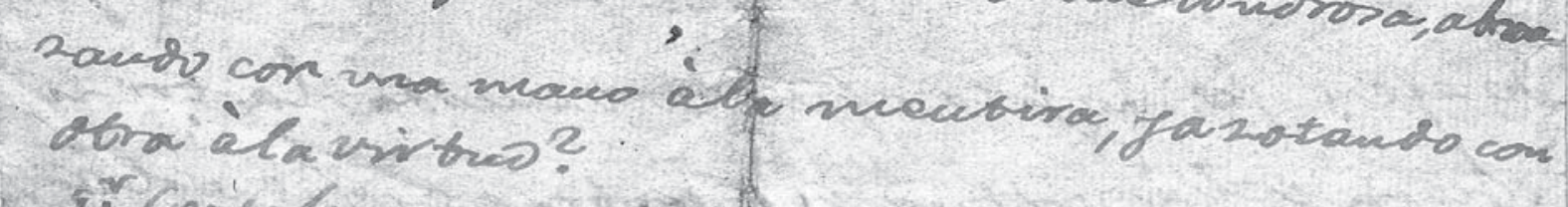
dr cinime.

CES.XVIII, núm. 22 (2012), págs. 23-37

33 
Fermin Canella Secades.

\section{ovido-1868 ceritto 21 de Enexo de 95}

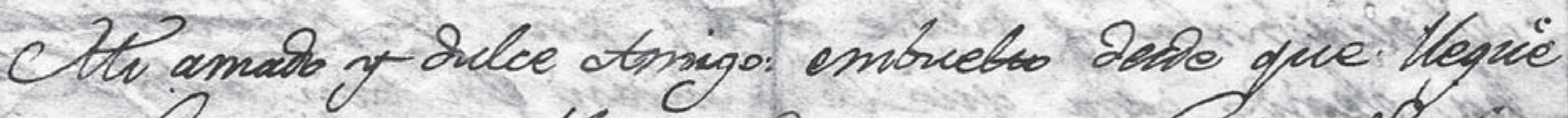

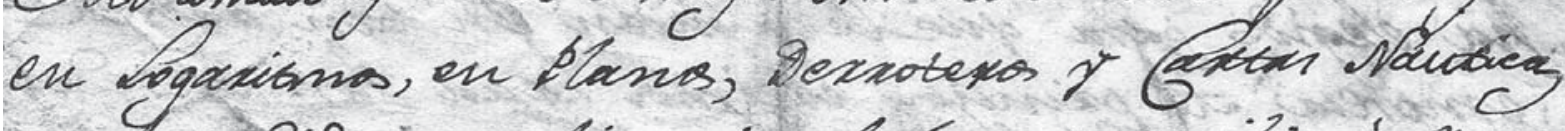
no the paside cumplin mi clatora de cercibir a uno. unatarga Getwimponiendole en ño. viage pax? maytor; $y$ con la experansa de poder haceslo tre ifo netaxdand de hix en hí eth pruecr de mi memoxia $y^{\prime}$ de ni asmor à vine periona, que en

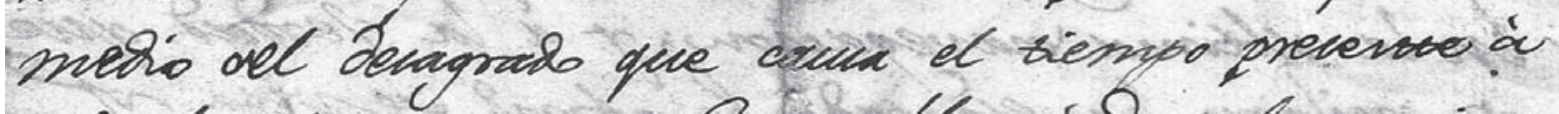
tod hombre que pienfa, ne obliga a dar dound in pastancia al viriv. Mainande pres entre tando ni

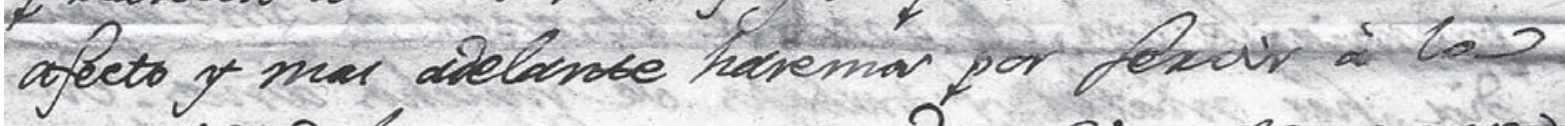

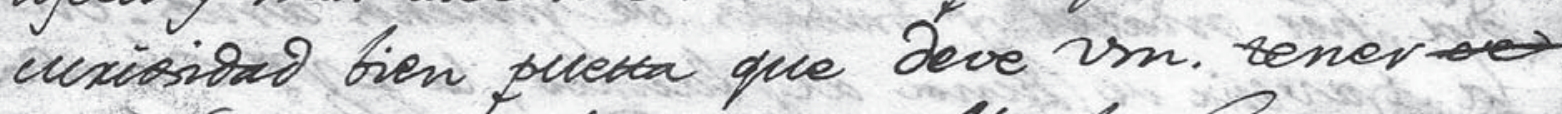
vobre noros. pates for hablo' de ellos la faceta fexo con un deiovir $\%$ confuceion con un deviden $\%$ corfucion, $y$ con encunces of promera taller dfue fe habrin hecho incseibler à

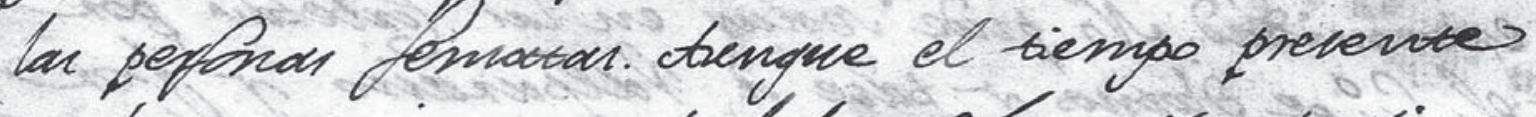

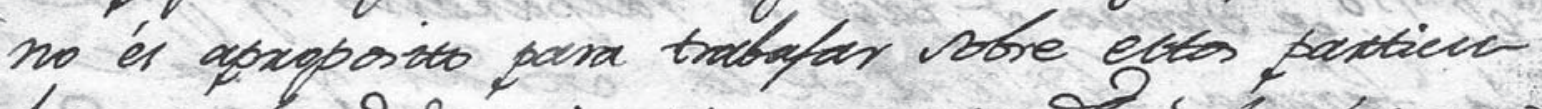

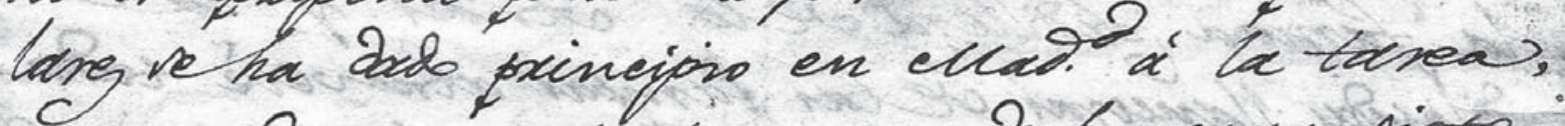

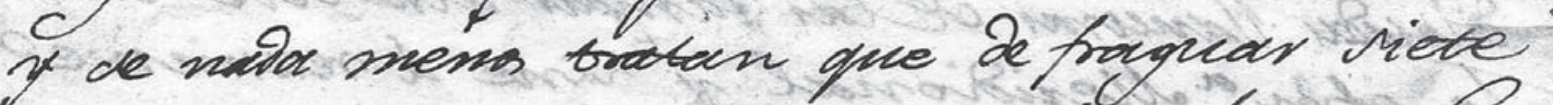

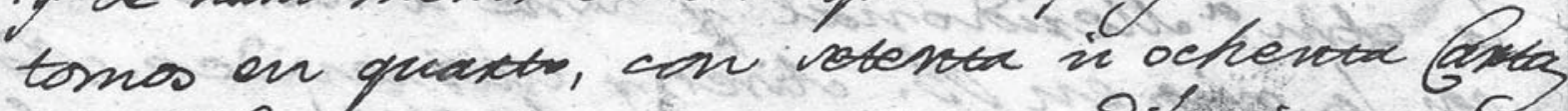
en otitar ceparado, dmen de un Dituro aces dibytos, cre traner, de evampar de aximaler y 
de otices obfetes de hivaciay natborals que fore? mui costia havin infoportable la obra paina el maytar numero de leetores. Cllal. estí encangado

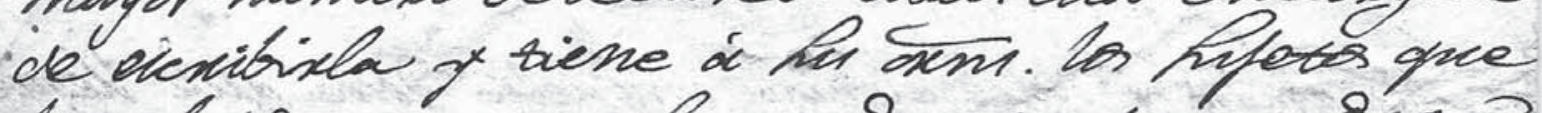
ha eleyido para que le andiden en tan aroria? empreva. Hepincipio cieimos haxid Iar. la neber cion, pers of ha dewanecib ge eiseranzal

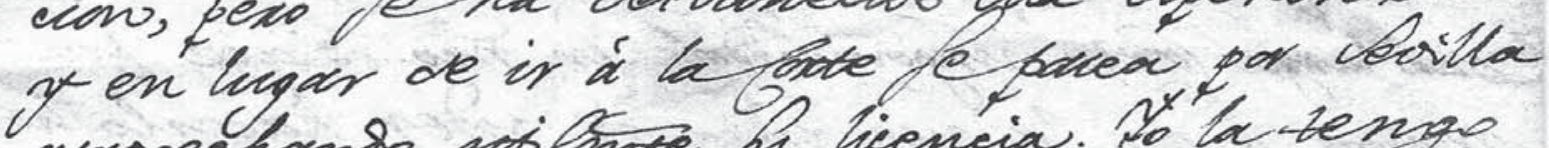

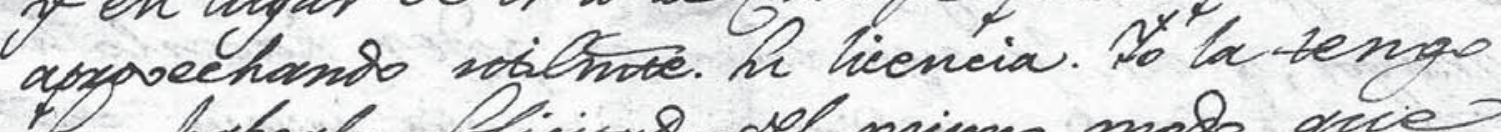
in haberla olliciads ol nimo mode gives otur de min Gmpañers ope padecimo mucho en la uttind navequcion; $y^{2}$ a la perdad ques de milappe ha exeapors he ctnis ore in. tal vex le conferea la savidencia panas parmingle con el qous, de abracear of im alfom rix, her maler ofrobutos de muchos años. En la travenia de Mina al Pacifece, la ef Olano,

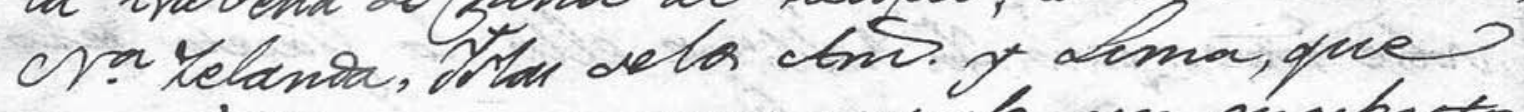
ho cast 9 movel de mar, contrife un eresebroto tan arraigad que Hequé d' dima en la rebima extrenibas. No pride vequir en lar opbould por? el co or otonós of pave or Pallsacrain

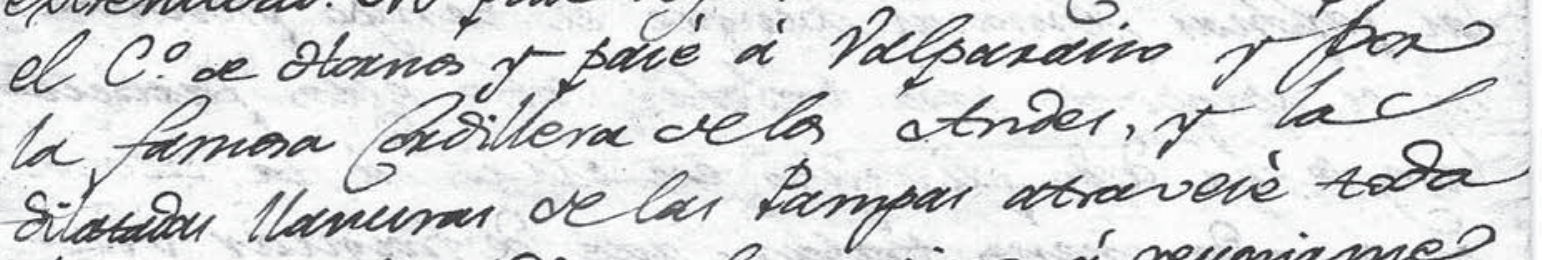
la ctur. Nexitional y vine á reunime? con los mias en B. ativer y cliontevideo. No me ha pelads per etta porcion la primosa de la zienxa, It flo me siele la srecipitacion an

CES.XVIII, núm. 22 (2012), págs. 23-37

35 
we he priad por uno Baifes riopros de tora

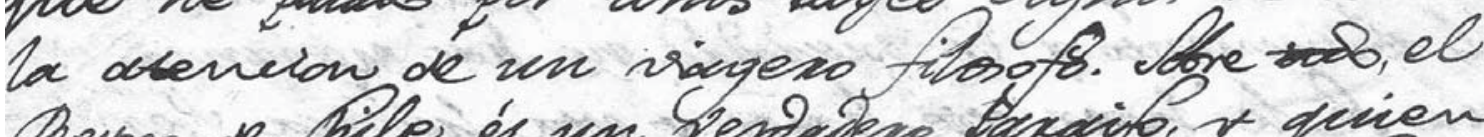
Reyno de fille és un herdadeno taxaijo, to quien pridere reunir tafo aó telo lo offetos ce hy

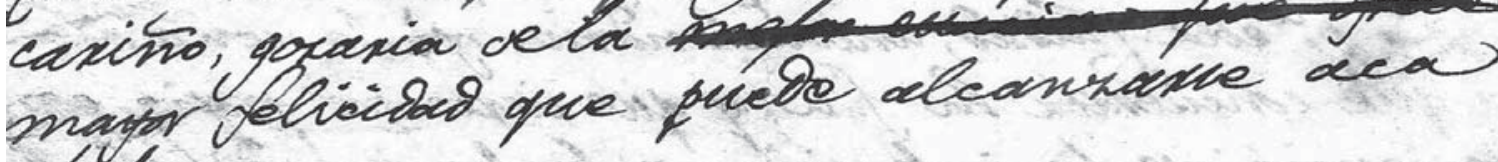
voly.

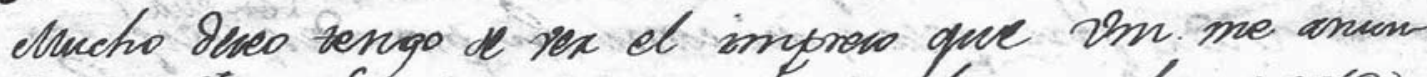
ia fore el Imitutio tutixiano, y, me cabe mucha parte

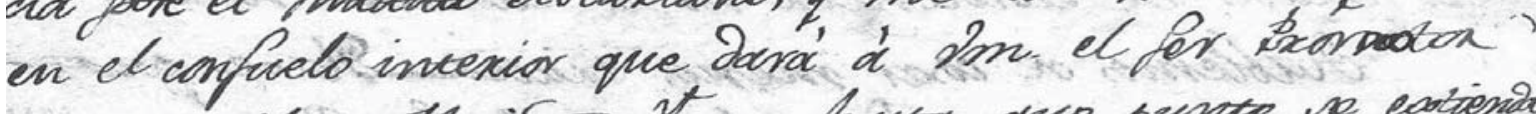

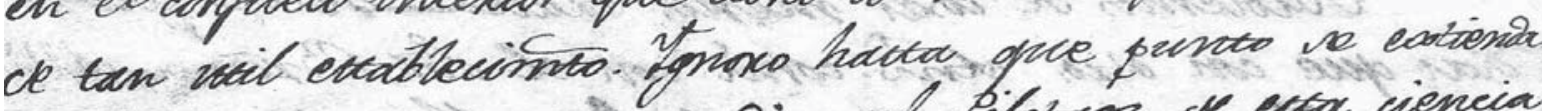
en él la instruccion pesturbia del pilotige, de ectac ciencia rivina que por los gramder pares que tha hecho en eves

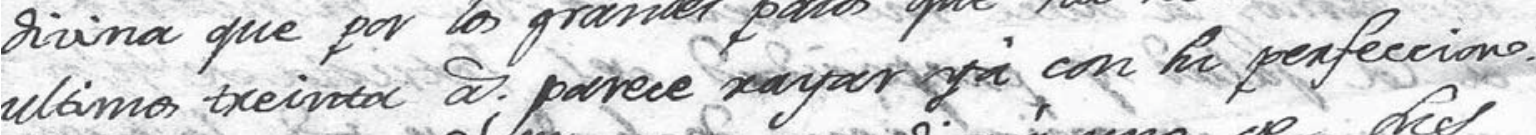
tearmos de pesder wno de euts riar disma de def teavamo de persen who a

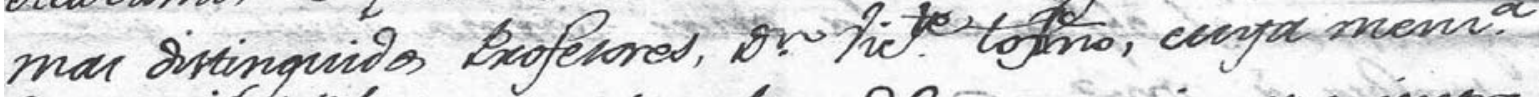

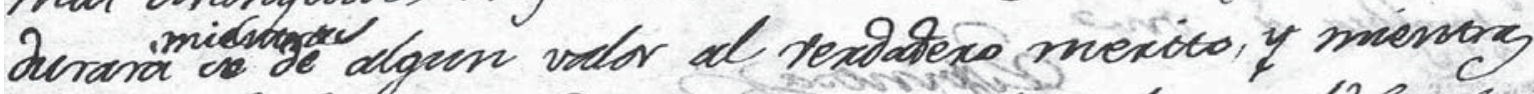

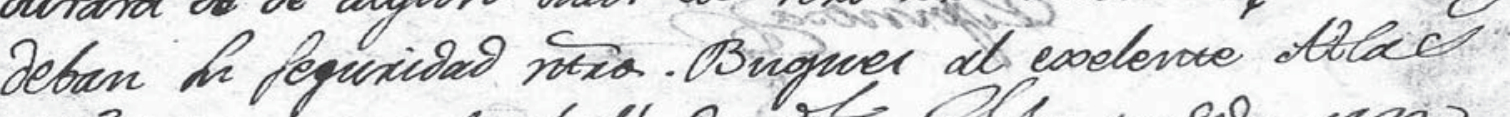

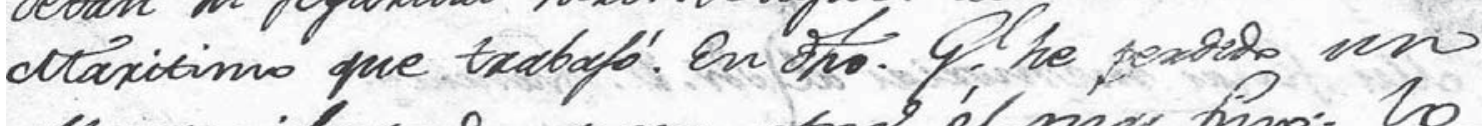

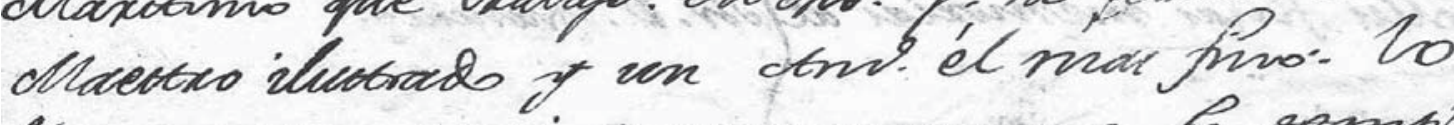
thera de um. mui de corarom uninge ha zemple

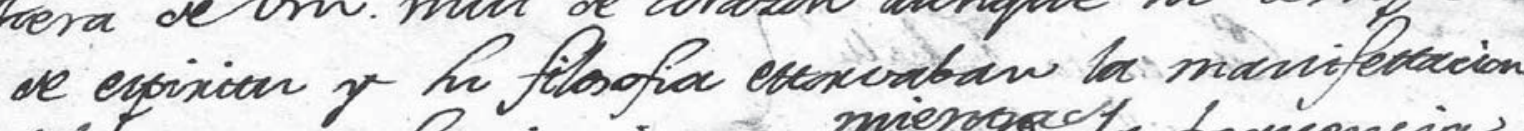

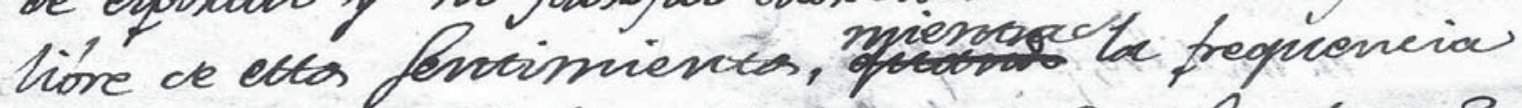

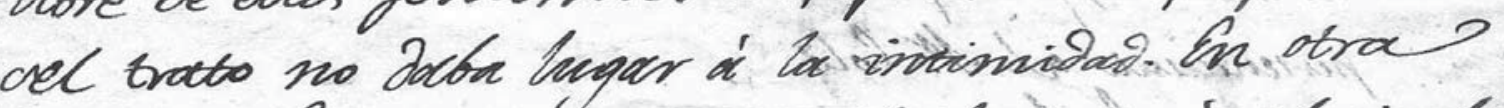

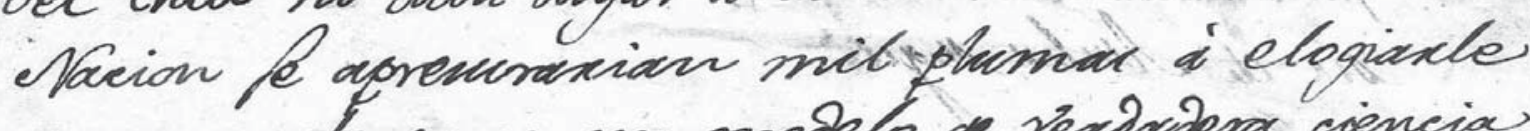
y proponexte como un modelo de rexdadera ciencia If patxicotirmo; pexo en la notra que muexts à los $63 \mathrm{C}$. de erad hace folo 5 que facamos de hi noquet 
alquin paxtidb, y vodes lo demar le defamos virir eno. el abatimiento y las scuxidad, no hai yperamia de que fe le haga ute hanor y exa fucticia. Mempre

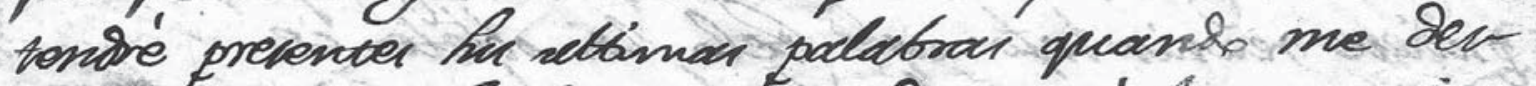

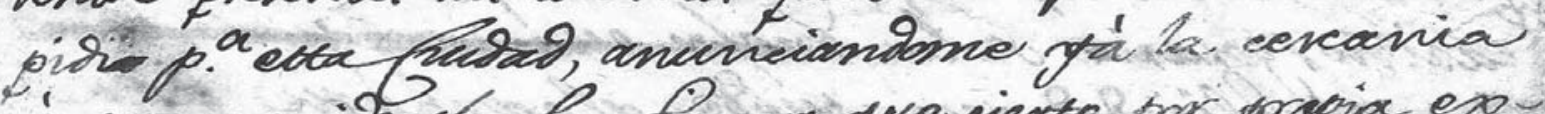
a que concideraba ha tin, y que ciexto por fordpia ep peviencia cela infrecticia ce lo homber defabes

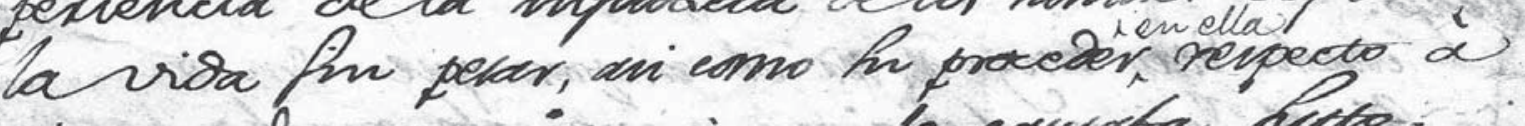

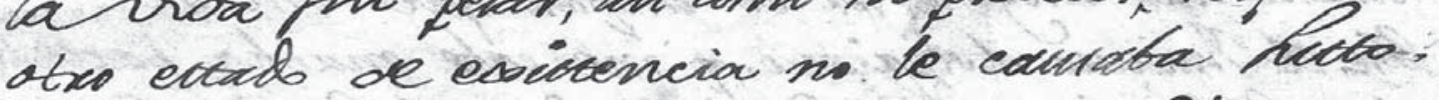

Otablemos de esar menos ixuted Abuce poed os

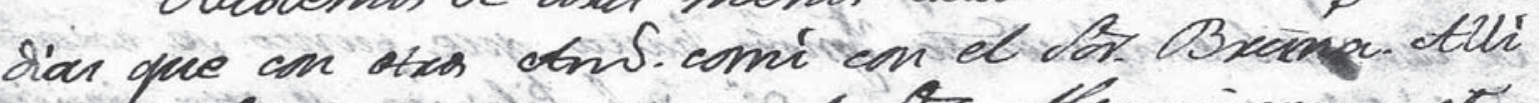

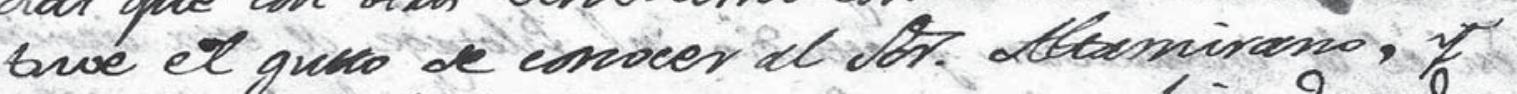
recosarntos la delee mennacia de in. bxindando

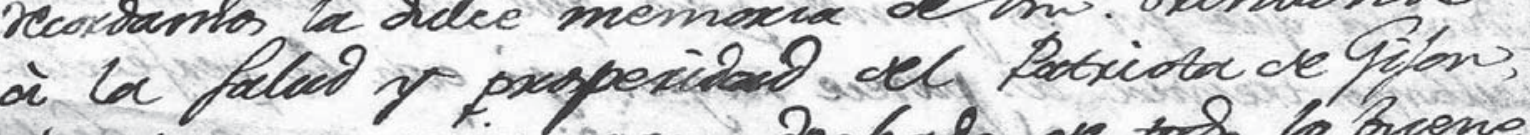
a quien yo mive emo dechads are tod lo bueno, it camo el oblero de la mar tienna amistad que profera a vn opmos as ?

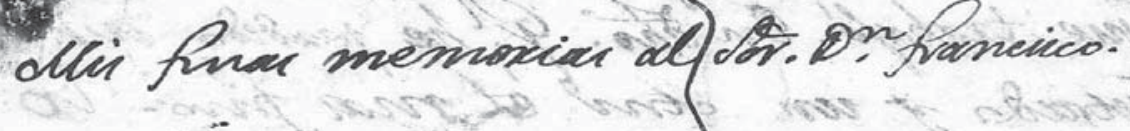

- Co carra ta hath

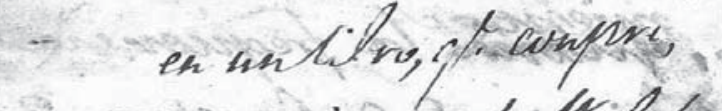

- pertenciente al fítolo.

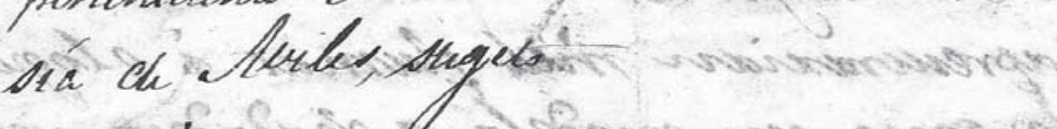
de mevils.

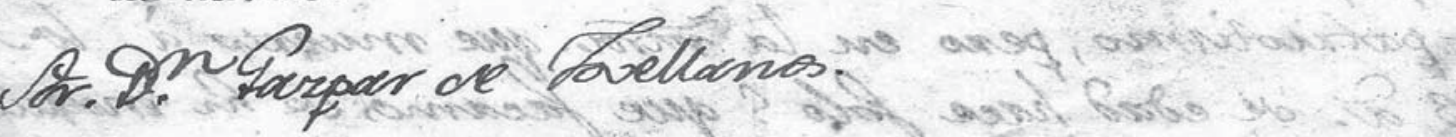

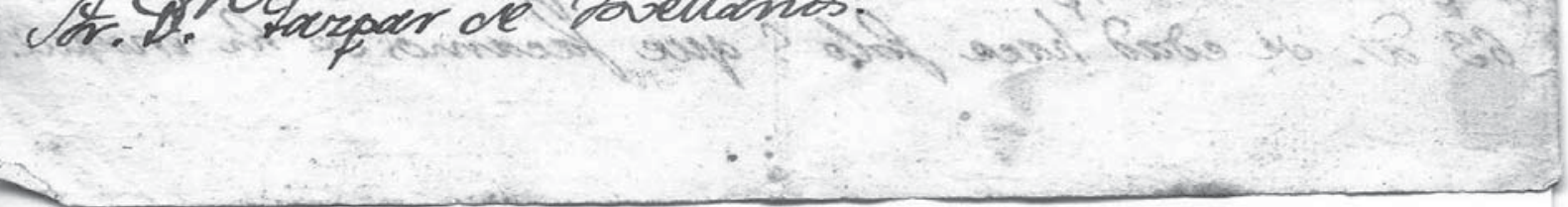

